\title{
Ocorrência do Mal-do-Panamá em Bananeira do Subgrupo Figo, em Piau, Minas Gerais
}

\author{
J. Clério R. Pereira' ${ }^{1}$ Joaquim R. Pereira ${ }^{2}$, Maria Eunice A. Castro ${ }^{3}$ \& Luadir Gasparotto ${ }^{1}$

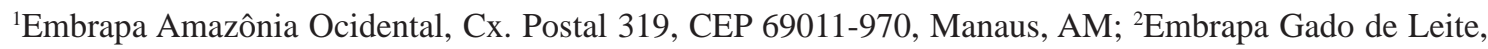 \\ R. Eugênio Nascimento, 610, CEP 36035-330, Juiz de Fora, MG; ${ }^{3}$ IMA/DDSV, Av. dos Andradas, 1220, \\ CEP 30120-010, Belo Horizonte, MG
}

(Aceito para publicação em 17/03/2005)

Autor para correspondência: José Clério R. Pereira

\begin{abstract}
Occurrence of the Panama disease in banana plants of the subgroup Figo in Piau, Minas Gerais

The Panama disease or Fusarium wilt, caused by Fusarium oxysporum f. sp cubense is the most economically important vascular disease of bananas (Musa spp.) in tropical countries. The disease causes premature death of adult plants near or throughout flowering. Fusarium wilt has been detected for the first time in the banana plant cultivar Figo Cinza, subgroup Bluggoe in the municipality of Piau, Minas Gerais, Brazil, suggesting an occurrence of race 2 of F. oxysporum $\mathrm{f}$. sp. cubense. This is the first report of F. oxysporum f. sp. cubense race 2 in the State of Minas Gerais and/or probably in Brazil.
\end{abstract}

O mal-do-panamá é a doença vascular da bananeira (Musa spp.) mais destrutiva nas regiões tropicais do mundo onde se cultivam bananeiras. A doença induz morte prematura de plantas adultas próximo ou durante o florescimento e as perdas podem atingir 100\% da produção dependendo da maior ou menor incidência. A doença tornase mais importante à medida que seu agente causal Fusarium oxysporum f. sp. cubense (E.F. Smith) Snyder \& Hansen pode sobreviver no solo, mesmo na ausência de hospedeiras, por até 50 anos. F. oxysporum f. sp. cubense apresenta quatro raças (Pereira et al., 2003. Embrapa Amazônia Ocidental, Circular Técnica, 20, 8p.), sendo que a raça 1 infeta cultivares dos subgrupos Prata e Gros Michel, a raça 2 infeta bananeirs do subgrupo Bluggoe, como as cultivares Figo cinza, Figo Vermelho ou Marmelo, Pelipita e Bluggoe entre outras; a raça 3 infeta plantas da família Heliconiaceae e a raça 4, sob condições de hipoxia, ataca cultivares do subgrupo Cavendish.

As plantas examinadas apresentaram amarelecimento das folhas baixeiras, ruptura do pseudopecíolo junto ao pseudocaule, e quando submetidas a cortes transversais do pseudocaule e rizoma, exibiam descoloração vascular interna em nível de bainhas situadas na porção mediana do pseudocaule, em formato de anéis concêntricos (Figura 1). No rizoma a região de maior vascularização na inserção do estelo - córtex apresentavam sintomas característicos do mal-do-panamá.
No bananal onde plantas da cultivar Figo Cinza ou banana Pão estão sendo infetadas por F. oxysporum f. sp. cubense plantas da cultivar Maçã, suscetível à raça $1 \mathrm{e}$ Grande Nine suscetível à raça 4, têm completado o ciclo produtivo, não apresentando quaisquer sintomas macroscópicos o que sugere tratar-se da raça 2 ou raça fisiológica 2 que ataca cultivares do subgrupo Figo.

Este é o primeiro relato da ocorrência de F. oxysporum f. sp. cubense, raça 2, no município de Piau, em Minas Gerais e, provavelmente, no Brasil.

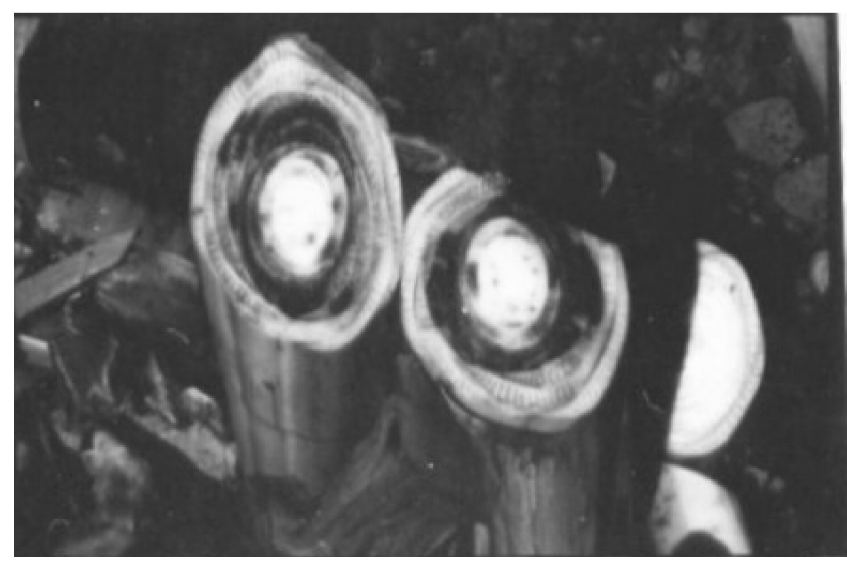

FIG. 1 - Corte transversal do pseudocaule de bananeira (Musa spp.) exibindo descoloração vascular em anéis concêntricos, causados por Fusarium oxysporum fsp. cubense. 